\title{
The Genealogy of Ancient Comedy in the Representation of Olga Mikhailovna Freidenberg (Russian Translation) $)^{1}$
}

\author{
Arkadiusz Bednarczuk (a); Sergey A. Troitskiy (translator) (b) \\ (a) Adam Mickiewicz University. Poznań, Poland. Email: a.bednarczuk[at]interia.pl \\ (b) Herzen State Pedagogical University of Russia/Saint Petersburg State University. \\ Saint Petersburg, Russia. Email: sergtroy[at]yandex.ru
}

\begin{abstract}
The article discusses the concept of genealogy and the cultural significance of the ancient comedy in the view of O. M. Freidenberg. For Freidenberg, the ancient comedy was a form of metaphorization of reality. The metaphor, like the symbol in Cassirer's philosophy, was interpreted by Freidenberg as the immanent product of the human spirit. Recognizing the similarity between the ideas of Cassirer and the reflection of Freidenberg, this study attempts to indicate the relationship between the literary concept in the context of Freidenberg and the theory of culture, which was the work of Cassirer. As with Cassirer, the original thinking was, in the Russian researcher's view, concrete, indivisible and figurative. The development of literature is the development of conceptual thinking, which became more and more abstract. The structure of ancient comedy was, therefore, the result of the development of human thought, the evolution of which Freidenberg saw, like Cassirer. The concept of the genealogy of comedy by Freidenberg, seen from the perspective of the Cassirer's theory of symbolic forms, is an original, consistent and logical hypothesis about the cultural significance of ancient comedy. Most of the interpretative problems it presents arise from the attempts to consider it in isolation from the cultural theory endorsed by Freidenberg, of which Cassirer was the author. The article is addressed to philosophers of culture, literary critics and historians.
\end{abstract}

\section{Keywords}

O. M. Freidenberg; Parody; Comedy; Myth; Ancient Culture; Metaphor; E. Cassirer

This work is licensed under a Creative Commons «Attribution» 4.0 International License

1 The original: Bednarczuk, A. (2010). Genealogia komedii antycznej w ujęciu Olgi M. Frejdenberg. In T. Obolevitch \& K. Duda (Eds.), Symbol w kulturze rosyjskiej (pp. 435-452). Kraków: WAM. 


\section{Генеалогия античной комедии в представлении Ольги Михайловны Фрейденберг (перевод на русский язык) ${ }^{1}$}

\section{Беднарчук Аркадиуш (a); Троицкий Сергей Александрович (переводчик) (b)}

(a) Университет Адама Мицкевича. Познань, Польша. Email: a.bednarczuk[at]interia.pl

(b) Российский государственный педагогический университет им. А.И. Герцена / Санкт-Петербургский государственный университет. Санкт-Петербург, Россия. Email: sergtroy[at]yandex.ru

\section{Аннотация}

В статье обсуждается концепция генеалогии и культурного значения античной комедии в изложении О.М. Фрейденберг. Для Фрейденберг античная комедия была формой метафоризации реальности. Метафора, как и символ в философии Э. Кассирера, интерпретировалась Фрейденберг в значении Имманентного творения человеческого духа. Признавая совпадение между идеями Кассирера и рефлексией Фрейденберг, следует попытаться определить взаимосвязь между литературоведческой концепцией Фрейденберг и теорией культуры Кассирера. Как и у Кассирера, первичное мышление было в представлении русской исследовательницы конкретным, неделимым и образным. Развитие литературы - это развитие концептуального мышления, которое становилось все более абстрактным. Таким образом, структура античной комедии была результатом развития человеческой мысли, эволюцию которой видели и Фрейденберг, и Кассирер. Концепция генеалогии комедии Фрейденберг, рассматриваемая с точки зрения теории символических форм Кассирера, является оригинальной, последовательной и логической гипотезой о культурном значении античной комедии. Большая часть интерпретационных проблем, которые она ставит перед собой, связана с попытками трактовать ее в отрыве от одобренной Фрейденберг теорией культуры, автором которой был Кассирер. Статья адресована философам культуры, литературоведам и историкам.

\section{Ключевые слова}

О.М. Фрейденберг; пародия; комедия; миф; античная культура; метафора; Э. Кассирер

Это произведение доступно по дицензии Creative Commons «Attribution» («Атрибуция») 4.0 Всемирная

1 Перевод с польского языка статьи Bednarczuk, А. (2010). Genealogia komedii antycznej w ujęciu Olgi M. Frejdenberg. In T. Obolevitch \& K. Duda (Eds.), Symbol w kulturze rosyjskiej (pp. 435-452). Kraków: WAM. 
Размышления Ольги Михайловны Фрейденберг об античной культуре, несмотря на всю их оригинальность, не получили особой популярности и долгие десятилетия были известны только узкому кругу специалистов ${ }^{1}$ На такую маргинализацию достижений российской ${ }^{2}$ ученой влияли не только реалии, в каких ей пришлось работать, но и быстротой, с которой о долге по отношению к ней хотели забыть другие исследователи. Это касалось даже самых известных из них, особенно М.М. Бахтина, который заимствовал от нее «больше, чем сам захотел в этом признаться» (Żyłko, 2007, p. 544).

Концепция генеалогии и культурной роли комедии О.М. Фрейденберг представляла собой гипотезу, которую следует рассматривать в контексте господствующей точки зрения о связи литературы и социального происхождения. Основной особенностью человеческой мысли было для автора умение метафоризировать реальность. Человек концептуализирует воспринимаемую действительность с помощью метафор, которые отражают его мировоззрение:

\begin{abstract}
Если мы встречаем одно и то же действие в виде реального и в виде имажинарного, если совершенно различные явления смешиваются в сознании одно с другим и если такие биологические факты, как утоление голода, как появление ребенка или смерть человека воспринимаются вопреки их реальной сущности, то ясно, что мы имеем дело с двумя явлениями, во-первых, с действительностью, во-вторых, с концепцией этой действительности в сознании (Фрейденберг, 1997, сс. 55-56).
\end{abstract}

Такое описание человеческого мышления, по крайней мере частично, развивает идею И. Канта о метафоре. По словам Канта, действие мышления может происходить только в результате владения языком метафорическим: «Наш язык полон таких косвенных изображений по аналогии, благодаря чему выражение содержит в себе не настоящую схему для понятия, а лишь символ для рефлексии» (Кант, 1966, с. 374). Познание, выходящее за пределы мира явлений, а значит, являющееся познанием метафорическим, не основано на сходстве между вещами, но предполагает полное сходство отношений, которые между ними происходят (Кант, 1965, с. 181, § 58). Метафора является своего рода мостом между миром явлений, доступных для восприятия человека, и миром его мысли. Однако концепция априоризма Канта ограничивалась сферой интеллекта, а Фрейденберг интересовалась специфической культурной ролью метафоры. Таким образом, представляется, что рассуждения Канта составляли определенную интеллектуальную атмосферу, в которой формировалась мысль Фрейденберг, но не были определяющими для представляемой ею согласованности взглядов.

Более важным для Фрейденберг были мысли В. Вундта, который частично развивал идеи Канта (особенно в области теории апперцепции и познания)

1 Огромную благодарность я приношу господину профессору Анжею П. Ковальскому за то, что он обратил мое внимание на важность осмысления философской интерпретации мышления О.М. Фрейденберг.

2 Автор намеренно использует слово «российская» для указания на принадлежность к культуре и языку, а не к периоду, в который Ольге Михайловне Фрейденберг пришлось работать и жить. 
и посвятил в своих работах много внимания процессу формирования и функционирования языка. Распространению неокантианства способствовала и известность среди представителей научного сообщества работ Э. Кассирера. Относительно последнего важным был тот факт, что, придя к убеждению, будто интеллектуальный синтез не является единственным средством формирования действительности, он предпринял попытку дополнить кантианство теорией наук о культуре. Как Кассирер, так и Фрейденберг упоминают в своих работах теорию Вундта. Однако это не означает, что русский вариант неокантианства был исключительно результатом освоения работ Вундта. Гораздо более очевидным кажется влияние философии символических форм. Впрочем, сама Фрейденберг обратилась к Кассиреру как к философу, который извлек окончательные выводы из концепции Канта об априорных формах чувственности и творчески применил их в исследовании мифологической реальности (Фрейденберг, 1997, с. 31).

В рассуждениях Фрейденберг метафорическое мышление, как принцип всякого восприятия реальности, имеет ряд черт, близких к концепции символического мышления в изложении неокантианца Кассирера. Метафора у Фрейденберг, как и символ в философии Кассирера, интерпретируется в качестве имманентного творения человеческого духа. Вместе с тем, она, как и немецкий философ, подчеркивает сильную связь людей с источниками впечатлений. Контакт человека с миром был первоначально прямым, основанным на образе, характере. Рассматривая отношения между искусством, религией и мифом, с одной стороны, и воспринимаемой реальностью, с другой, Фрейденберг отмечает распространенные метафоры, которые объясняли семантику культуры. Аналогичным образом для Кассирера язык, мифорелигиозный мир и искусство выступают как особая символическая форма:

Во всех них выражается тот основной феномен, что наше сознание не довольствуется тем, чтобы воспринимать воздействие внешнего, а сочетает всякое воздействие со свободной деятельностью выражения и пронизывает первое последним. Мир самостоятельно созданных знаков и образов, исполненный самостоятельности и изначальной силы, противостоит тому, что мы называем объективной действительностью, и главенствует над ней (Кассирер, 2000, c. 394).

Когда Фрейденберг утверждает, что человеку недостаточно просто воспринимать реальность, но творя искусство, он нуждается в метафоризации различных аспектов мира, исследовательница фактически повторяет один из основных тезисов создателя теории символических форм. Ведь для Кассирера очевидно, что в процессе культуротворчества

сознание не ограничивается тем, чтобы просто иметь чувственное содержание, a [...] оно его из себя производит. Сила этого производства и есть то, что оформляет чистое содержание ощущения и восприятия в символическое содержание. В нем представление перестало быть просто воспринятым извне, а стало тем, что создается изнутри, чем-то таким, в чем господствует основной принцип 
свободного образования. Это и есть та работа, которую мы видим проделанной в отдельных «символических формах»: в языке, в мифе, в искусстве. Каждая из этих форм не только зарождается в чувственном, но и остается постоянно заключенной в область чувственного (Кассирер, 2000, с. 396).

Для Фрейденберг такая способность восприятия мира через человека и метафоризации его различных аспектов была основным компонентом обряда, мифа и искусства.

Несмотря на развитие человеческой мысли, которая начинает отходить от мифического - или только мифического восприятия действительности, метафора оказалась чрезвычайно долговечной. Даже постепенная потеря первоначального смысла не уменьшила ее силы. Она стала элементом структуры литературного произведения, а ее первоначальное значение подверглось переосмыслению.

Обряд и миф, создаваясь метафорической интерпретацией действительности, закрепляют метафоры, стабилизуя и узаконяя их, и тем самым обрекают на полное уничтожение их былого смысла. И все же именно здесь, в обряде и мифе, подготовляется будущая длительная жизнь метафор, которые начнут функционировать стороной этого забытого смысла. Перед нами, таким образом, двойной процесс. С одной стороны, тот или иной смысл не может реально существовать без одновременного отложения в виде известной структуры. С другой стороны, сама структура, представляющая собой морфологическую сторону смысла, является поводом для смысловой расшифровки и порождает снова смысл. [...] То, что впоследствии составляет литературные сюжеты и жанры, создается именно в тот период, когда нет еще ни жанров, ни сюжетов. Они складываются из мировоззрения первобытного общества, отлитого в известную морфологическую систему; когда смысл этого мировоззрения исчезает, его структура продолжает функционировать в системе новых осмыслений (Фрейденберг, 1997, с. 108).

Таким образом, мы имеем здесь дело с процессом, в котором первичная метафора, способ мышления о мире, становилась литературным мотивом или структурировала литературное произведение. Хотя первоначальный вид ее стал медленно меняться, метафора все еще сохраняла свою силу творения. Это было связано с особенностями специфического мышления, которому чуждо было стремление усомниться в восприятии существующей реальности: «особенность первобытного мышления в том и состоит, что оно не преодолевает старого мировоззренческого наследия, так как у этого мышления нет реальных предпосылок для сдвигов, для создания подлинно новых форм; старое в непереваренном виде уживается с относительно новым, что вырабатывает сознание в последующие этапы своего развития» (Фрейденберг, 1997, c. 107).

Некоторые исследователи в рассуждениях Фрейденберг о начале литературы усматривали влияние работ 3. Фрейда, считая, что для русской мысли следование концепции Фрейда имело большое значение ${ }^{1}$. Похоже, несмотря

1 Такое мнение, например, высказывается в: Граевский, 2005, p. XXVI. 
на видимые сходства, влияние Фрейда на мысль Фрейденберг не было философски последовательным, т.е. не приводило к аналогичным выводам. Фрейденберг, впрочем, довольно скептически относилась к теории Фрейда и склонялась к мнению, что он не вносит ничего нового в исследования мифа (Фрейденберг, 1997, с. 29). Так же думал Кассирер, который, поддерживая критику в отношении концепции Фрейда, отметил ее сущностную близость к натуралистической интерпретаций мифа:

\begin{abstract}
Исследователи сравнительной мифологии говорили о солнце, луне, звездах, ветре, облаках так, как если бы это были единственные темы, занимавшие мифологическое воображение. Фрейд просто сместил сцену, на которой происходили мифические рассказы. Не представляют они, по его мнению, великой драмы природы. То, что они нам рассказывают, это скорее вечная история о сексуальной жизни человека. От доисторических времен до настоящего времени человека преследуют одни и те же два основных желания. Желание убить собственного отца и жениться на собственной матери появляется в детстве человечества так же, как в жизни каждого отдельного ребенка, в самых неожиданных ипостасях и метаморфозах (Cassirer, 1946, pp. 35-36).
\end{abstract}

Взгляды Фрейда, как писал далее Кассирер, относились к метафизике, которая уходила корнями в традицию немецкой философии XIX века и была связана с рефлексией А. Шопенгауэра. В отличие от Г.В.Ф. Гегеля, для которого, исторический процесс представлялся сознательным и рациональным, Шопенгауэр считал, что мир не является творением разума:

Он иррационален по самой своей сути и идее, поскольку является порождением слепой воли. Сам интеллект - это не что иное, как одно из последствий этой слепой воли, создавшей его в качестве средства для собственных целей (Cassirer, 1946, p. 31).

Именно в философии Шопенгауэра, который половой инстинкт признал за «истинного правителя» биологического вида человека, можно в каком-то смысле найти зачатки концепции Фрейда. По мнению австрийского ученого, миф оставался «патологическим» явлением, но начинал пониматься как система, отражающая эмоции и психическую жизнь человека. Таким образом, миф рассматривался как продукт человеческой психики, которую не следует путать с сознанием. С другой стороны, проблематичным было обосновать связь между эмоциональностью и сексуальной сферой, в частности, с боязнью инцеста. Как утверждал Кассирер, Фрейд находился в заблуждении, что понимание содержания мифа позволяет понять язык мифа: «Недостаточно ведь просто знать содержание мифа, чтобы понять его природу и характер» (Cassirer, 1946, р. 33). Фрейд справедливо видел смысл мифа в эмоциональной сфере человека, но ему был свойственен редукционизм, суть которого сводилась к снижению эмоциональности за счет неосознаваемых сексуальных желаний. Но что было хуже, он не понимал, что даже если в этой концепции и есть капля истины, то содержание мифа с его культурным генезисом и значением вряд ли можно свести сугубо к боязни инцеста. 
Кассирер утверждал, что содержание мифа было второстепенным, а превращение его в основной предмет исследования объясняется сведением мифа к «истории».

Фрейденберг предприняла попытку понять семантику мифа, но содержание «истории» было не единственным предметом разысканий, так как здесь присутствовала также рефлексия над языком мифа. В трудах Фрейденберг, что могло бы у исследователей вызвать ассоциации с наследием Фрейда, также появились понятия «тотема» и «тотемизма». Однако эти концепты не имели теоретического фона, связанного с именем Фрейда. Она использовала термины «тотем» и «тотемизм»в основном для иллюстрации сравнительной схемы в греческой литературе. Для Фрейденберг показательным в рамках этих сравнений был материал, взятый из Илиады, где Гомер противопоставлял два компонента: один отражал активные характеристики охотника, другой - пассивные черты жертвы. По мнению российской исследовательницы, такая картина сравнений отразила антитезу охотника - жертву или оппозицию кланового сообщества и жертвы тотема, убитой и съедаемой его членами. А. Ковальский, описывая ход мыслей О. Фрейденберг, заметил:

Первоначально родовая община не была чисто биологическим сообществом. Она создавалась посредством приобщения к тотему (например, через потребление тотема). Таким образом, участие в сообществе было возможно не только для родственников, но и для людей, которые когда-то были врагами. Это также относилось к умершим, богам, героям и т.д. Никакие естественные для современного европейца деления не использовались в контексте магической унификации. Каждый мог стать тем объектом или субъектом, который как раз оказывался в поле сопоставления. [...] Принципы сопоставлений, перенесенные в плоскость действий, не только допускают взаимное приобретение признаков собранных объектов и субъектов, но и вхождение в состояния, полярно отличные от наиболее часто испытываемых. Таким образом, О. Фрейденберг, например, употребление в пищу тотемной жертвы могла интерпретировать как своего рода самопоедание. Сама жертва стала ею в результате контакта и словесного совпадения с предполагаемыми объектами. Сопоставление обоих объектов магической повинности, их сближение, вызывало своеобразную контаминацию и, наконец, симметрию их идентичностей. Поскольку смерть так близко соседствовала с жизнью, акт самоуничтожения был актом возрождения. Съедение, ритуальное потребление жертвы происходит после смерти, распада, но, как пища, вносит новый опыт проживания, возрождения (Kowalski, 1999, p. 71).

Таким образом, концепция тотема и тотемизма, которая представляет собой существенный компонент размышлений Фрейденберг о структуре сопоставлений, позволила ей сделать о примитивной культуре иные выводы, чем те, к которым пришел Фрейд.

В концепции Фрейда само понятие метафоры отличается от понятия архетипа. Архетип связан с «естественными» и докультурными источниками человеческого поведения, которые в процессе становления цивилизации подвергались культурному регулированию. В человеческой психике есть подсознательная (Id) сфера, в которой культура страхов и желаний является 
кумулятивной. Эти бессознательные мысли определяют действия и чувства реальности человека. Они подавлены Супер-Эго, которое играет роль своеобразного регулятора деятельности. Культура создает своего рода барьер, который ограничивает «естественное поведение» человека, но архетип попрежнему актуализируется персонально. В сущности, архетип становится структурой, которая зависит от индивидуальной психики и еe реакции на культурное регулирование. С другой стороны, метафора в представлении Фрейденберг была связана с историей общественной мысли и общественного мировоззрения. Также, по мнению российского автора, сюжет не являлся результатом работы индивидуальной психики или результатом определенного мировоззрения.

Наконец, следует допускать, что поиск сходства и полагание взаимосвязи между мыслью Фрейда и Фрейденберг, по крайней мере, в плоскости философской, лишены глубоких оснований. Гораздо более очевидны зависимости, которые существуют между литературно-теоретической концепцией Фрейденберг и культурной теорией Кассирера. Это заметно уже в том, как воспринимался литературный процесс. Для Фрейденберг он представлялся историко-социальным, его содержанием был переход от образа к концептуальному восприятию реальности. Для Кассирера первоначальное (в понимании русской исследовательницы) мышление было конкретным, неделимым и живописным. Образ, не в смысле изображений на холсте, а как способный восприниматься объект в пространстве, был для примитивного первобытного человека познавательной категорией (см. Фрейденберг, 1978, c. 27). Развитие литературы - это развитие концептуального мышления, которое делалось все более абстрактным. Образ медленно освобождался от оков реальности и становился закваской для понятия.

Не следует, однако, рассматривать это явление в качестве схемы для эволюции всей человеческой мысли. По словам Фрейденберг, человек не стал думать образами, а потом - понятиями. Для нее это терминологическая проблема. Первобытный человек обладал понятиями, но конкретными, основанными на образе и далекими от абстракции современной мысли. Они были скорее схематическими диаграммами, которые позволяли распознать вещи и процессы, а также вещи и отношения между ними (см. Фрейденберг, 1978, с. 19). Первоначально мышление не знало формально-логической причинности, было антикаузальным (причинно-следственная последовательность в нем отсутствовала), а прошлое не исключало одновременности с настоящим. Трактуемое таким образом понятие близко к первометафоре, предоставлявшей возможность исследовать и обобщать мир, но далекой от абстракции, используемой сейчас. В исследованиях Фрейденберг метафора имела два значения: с одной стороны, это была универсальная познавательная категория, интерпретированная в духе неокантианства, с другой - специфическое литературное произведение. 
Структура античной комедии, коей российская исследовательница уделяла много внимания, была результатом развития человеческого мышления, которое она гипотетически предполагала.

В первобытном мышлении, а значит - и в древней комедии, сатира отсутствовала. Сатирическое мышление - обобщение, возникшее из-за появления понятийного мышления. Сатира всегда имела в виду явление в целом. Первоначальное мышление, напротив, использовало только пародию. По словам Фрейденберг:

пародией называется подражание, при котором величественная форма наполняется ничтожным содержанием. Пародия есть имитация возвышенного посредством жалкого, несоответствие содержания и формы, передразниванье, перевод с трагического на комическое (Фрейденберг, 2006, с. 230).

Сущность древней пародии, вместе с тем, не сводилась ни к издевательству, ни к имитации. Она была связана с высоким:

Наблюдение над образцами пародии показывает, что связь ее с религиозными обрядами и словесами или её приуроченье к религиозным праздникам не случайны: первоначально пародировалось именно все самое священное боги и культ, и перенесение пародии на «власть предержащую», на царей, правителей, народное собрание - парламент, на судей и все основные гражданские формы было вторичным (Фрейденберг, 2006, с. 235).

Трактовка комедии как тривиальной сатиры - неуклюжая модернизация сущности архаического мышления. Связь пародии с возвышенным была настоящей корреляцией в архаическом способе мышления. В мышлении эта связь насмешек с возвышенным была так же очевидна для автора, как и отношение солнца к тени. Пародия демонстрировала один из примеров биполярного мира, представлявшего собой неделимое единство. Отношения разных пар, составляющих когнитивные схемы - приближения, по мнению Фрейденберг, являются внутренним следствием комплементарности (взаимодополняемости) человеческого мышления, в котором не было места для оппозиции (борьбы противоположностей).

Аналогичные замечания можно найти у Кассирера, который, анализируя особенности первобытной мысли, утверждал, что:

\begin{abstract}
Мифологическое ощущение пространства было связано с самого начала с некоторыми физическими фактами: восприятием оппозиции дня и ночи, света и тени... Человек мифа начинал свое бодрствование с восходом солнца. Отражение в сознании человека чередования дня и ночи становится его первоначальным органом мышления, одним из источников его духовных возможностей и началом культурной эволюции человечества (Sójka, 1988, p. 57n).
\end{abstract}

Чтобы сотворить, например, представление о жизни и смерти как явлениях, которые начинают и обязательно завершают любое человеческое существование, уже нужно иметь четкую точку зрения на индивидуальное и всеобщее. Человек, отличающий свою человеческую сущность от мира природы, в размышлениях о себе противостоящем внешнему миру, должен и 
явления, становящиеся его потребностью, также отделять от жизни природы. В созданном людьми мифе первоначально не было понятия индивидуальной личности, которая была бы строго отделена от внешнего мира:

Только в процессе эволюции мифа постепенно формируется понятие человека, личности, категория «Я». Эти процессы были связаны не с какой-либо формой рефлексии, а, в основном, со сферой действия. Вся мифологическая реальность погружена в практическую атмосферу, человек мифа имеет цель не столько думать о мире, сколько взаимодействовать с ним - поступком, жестом, словом (Sójka, 1988, p. 60).

Тема единства субъекта и объекта, то есть познающего человека и познаваемого мира также была важным мотивом размышлений Фрейденберг. Подобная изначальная неразделенность предполагает существование только образного мышления. Не существовало качеств, понимаемых исключительно как объект спекуляции, которая, пользуясь абстрактным понятием, отделяла бы объективные качества от самих объектов. Человек не был способен так интерпретировать качество предметов, чтобы их обобщать, он мог представить их только в единстве, физическом присутствии (см. Фрейденберг, 1998, сc. 234235). Описывая это неимение качественного понимания представлений, которые вели к их семантической эквивалентности, Фрейденберг упомянула работу Х. Усенера (см. Фрейденберг, 1997, с. 23). Справедливости ради стоит отметить, что и Кассирер ссылался на Усенера в своих рассуждениях. Согласно Кассиреру, самое главное в концепции Усенера состоит в том, что божество и язык, который называет это божество, не относятся к двум разным источникам, но имеют единое начало в мифе, базируются на активном сознании субъекта (см. Andrzejewski, 1980, p. 138). Таким образом, метафоричность языка не представлялась исключительно как эффект многозначности слов. Для Фрейденберг метафора также знаменовала не тривиально понимаемую полисемию, а некий способ мышления, своеобразную кассиреровскую символическую форму.

Интерпретируя культурные значения античной комедии, Фрейденберг особо подчеркнула оригинальные отношения, которые существовали между философией, мистериями и мимом (см. Фрейденберг, 1978, с. 240). Античный мим представлял собой театральную форму, которая, правда, изначально не была только пространством смешного. Комедианты не подражали людям, но имитировали стихии. Иллюзионисты, комики и акробаты занимались в первую очередь природой. Они обладали полномочиями вызывать и делать то, что традиционно относилось к функциям древних богов, мудрецов, философов. Они становились подобны богам из Эпоса, которых мы застаем в описании, когда они творят чудеса, воздействуют на стихии, на чувственно воспринимаемую данность. Объектами подражания в миме являлись силы, которые в философии фюзиса были первоэлементами, началом и принципом бытия. «Чудеса» мимов похожи на теургии древних философов, обладавших способностью исцелять и влиять на видимую реальность. 
На ярморочной сцене, где разыгрывалось действо, зрители видели не шарлатанов, а наделенные телом стихии. Появлялись молнии, туман, различные животные. Магический опыт, легший в основу представлений о мире, богах и мудрецах, которые были первыми философами, стал основной составляющей мима. Демонстрация «чудес» в миме имела свою аналогию в мире вещей, в бытии, в мистериях (см. Фрейденберг, 1978, с. 238). Античный мим был визуализацией, смысл которой состоял в простоте передачи. Он имел форму, соответствовавшую первоначальному, образному мышлению. Мимы в древности назывались, помимо других наименований, aretholog (арэтологами). Это не означало, что в центре их внимания оказывалось абстрактное понятие добродетели. Сам смысл слова «этос» больше касался сферы чувственного внешнего облика. Еще у Гомера arethe было свойством не только человека или бога, но могло относиться также к животному или даже к неодушевленному предмету. Исходя из контекста, в котором это слово появилось в эпосе, можно предположить, что термин являлся синонимом внешнего, телесного вида (см. Фрейденберг, 1978, с. 235).

Развитие визуального мышления приближало мим к мистериям и философии, для которых основное значение также сосредотачивалось во внешнем виде. Среди многих названий мимов особенно лаконичный термин deikelon (dikelon) соотносится с мистериями. Древние словари переводили deikelon как mimemata («подражание, имитация») и ekasmata («изображение, образ») (Фрейденберг, 1978, с. 237). Корень этого слова показывает, что суть деятельности мима нужно было экспонировать. На основании древних переводов следует полагать, что суть мистерий сводилась именно к тому, чтобы продемонстрировать тайну. Важнейшей частью Великих Элевских Мистерий была epopteia, то есть «видение», «зрение». В темноте храма появляются всполохи пламени, а затем священник в полной тишине показывает секретные предметы, спрятанные в корзине. Мистерии - событие, которое «указывало» и которые можно было «увидеть». Как утверждал Буркерт: «мистерии были arrheta, "невыразимыми", но не в том смысле искусственной секретности, используемой для возбуждения любопытства, а в том, что самое важное и самое главное в них всегда за пределами возможностей вербализации» (Burkert, 1987, p. 69). Как заметил Аристотель, подвержение посвящению не дает каких-то знаний, но позволяет испытать (pathein) (Arystoteles, 1952, p. 87). Слово pathea («ощущение») присутствует также у Геродота, который таким образом определял сущность мистерий (Геродот, 1972, сс. 133-134). Можно предположить поэтому, что внимание Аристотеля отражало первичное и все еще ощущаемое переживание мистериального культа, самым возвышенным и самым захватывающим моментом которого было представление «невыразимой» тайны. 
Анализируя структуру мима, Фрейденберг заметила, что важную роль играла загадка (үрі́юо). Присутствие в миме загадки ясно указывает на его явную связь с религиозным смыслом и с философской диалектикой.

К аналогичным выводам о взаимоотношениях философии и загадки независимо от Фрейденберг пришел современный философ Ж. Колли, рассуждения которого позволяют в полной мере оценить новаторство Фрейденберг. Как утверждает итальянский исследователь, изначально загадка в Древней Греции тесно связана с пророчеством. Только в архаическую эпоху оно начало отделяться от божественного царства и стало предметом человеческой борьбы за мудрость. Первоначально конкуренция была областью пророков, мудрость которых воспринималась как эффект божественного вдохновения. Как пишет Колли:

[...] вместе с перемещением загадки в человеческую сферу, с угасанием чувства ее божественного происхождения становится все более очевидным, что ее формулировка содержит в себе противоречия. [...] Раньше бог подсказывал ответ оракулу, а «пророк», повторяя за Платоном, был просто переводчиком слова божьего и еще полностью принадлежал религиозной сфере. Потом бог через Сфинкса бросил загадку, угрожающую смертью, и одинокий человек должен был решить ее, чтобы спасти собственную жизнь. Наконец, два пророка, Кальхас и Мопсос, сражались друг с другом, чтобы разгадать эту загадку: Бог больше не участвовал, земля все еще была религиозной, но появился новый элемент, конкуренция, агонизм, который в этом случае был борьбой за жизнь и смерть. Еще шаг - и религиозный фон исчез, на первый план вышел сам агонизм, борьба двух людей, чтобы получить знания: они уже не были пророками, они были мудрецами и пытающимися завоевать титул мудреца (Colli, 1989, pp. 56-57).

Сначала религиозная роль загадки была раскрыта в форме ответа, данного оракулом Аполлона: «Владыка, тот, чьё прорицалище в Дельфах находится, не глаголет, не скрывает, зато намекает [знаками указывает]» (Гераклит, 2012, c. 173). Неправильно понятый знак в форме загадки мог сбить с пути и таил опасности. Диоген получил подсказку от оракула в Дельфах, которая рекомендовала «впечатывать деньги». Этот, казалось бы, однозначный стимул для подделки монеты, Диоген понял правильно, посвящая себя переоценке через философию любого обязательного обычая (Gigon, 1959, p. 70). Основатель школы стоиков Зенон должен был догадаться, что такое «спариться с мертвыми». Он тоже понял все правильно и начал изучать произведения древних философов (Gigon, 1959, p. 70).

Наиболее известным примером неправильной интерпретации ответа, данного прорицательницей, была подсказка, которую получил Крез. Она предсказала, что, выступив в поход против персов, тот «сокрушит великое государство» (Геродот, 1972, с. 26). Крез ошибочно понял пророчество и выступил против персов. Он действительно уничтожил государство, но свое собственное. Это не повлияло на славу прорицательницы, потому что, когда Крез, уже плененный, обратился к ней снова, полный сожалений, она 
обвинила его в неправильном толковании гадания (Геродот, 1972, с. 40-41). Она не дала ясных инструкций, ее слова только «дали пищу для размышлений». Как пишет Колли:

Поэтому считалось, что в некоторых мистических обстоятельствах отдельные переживания оказываются невыразимыми: в этом случае слова загадок раскрывают то, что является божественным, скрытым, что является неотъемлемым и неосязаемым. Слово неоднородно относительно того, что предназначено говорящим (для сообщения), поэтому оно обязательно неясно (Colli, 1989, p. 53).

Древние источники часто называли загадку проблемой, т.е. препятствием. Термин «проблема» также занимает важное место в языке диалектики. У Платона слово proballein использовано в качестве определения чего-то странного или чего-то диалектичного (Colli, 1989, p. 79). Наиболее полное определение загадки было дано Аристотелем: «В самом деле, идея загадки та, что, говоря о действительно существующем, соединяют вместе с тем совершенно невозможное» (Аристотель, 2007, с. 57). Как утверждал Колли:

Принимая, что путем объединения невозможности Аристотель понимает формулирование противоречий, его определение говорит, что загадка это противоречие, которое наводит на нечто реальное, а не то, что не показывает ничего, что в случае противоречия является правилом. Чтобы это могло произойти, - добавляет Аристотель, - не следует сопоставлять слова в их обычном понимании, но не нужно избегать использовать их в переносном значении. Поэтому использование метафоры связано с началом мудрости (Colli, 1989, p. 56).

Удивительное формальное совпадение между загадкой и философской диалектикой не только дает возможность рассматривать загадку как звено между мимом и философским диалогом, но и позволяет определять религиозные источники представленной на сцене загадки. Древний мим, используя такую форму, предложил способ познания, в которой главную роль стал играть философ-мудрец, тот, кто вопрошал у оракула. Мим не ограничивался указанием образа, а оперировал логосом - своеобразным знаком, позволяющим понимать тайну. Неоднозначность слов, адресованных Диогену и Зенону, допускала интерпретацию, которая коренилась в словах и не отсылала ни к чему иному. Логос фактически играл роль, похожую на функцию образа в предфилософской культуре: знака, содержащего в себе весь смысл. Проблема как препятствие, которое можно преодолеть, обратившись к самому этому препятствию. В случае с оракулом характерным можно считать ответ, который получил Фемистокл, спрашивая о способе защиты от персов. Он интерпретировал «деревянную стену», что приказала построить прорицательница, как флот, в отличие от других афинян, которые поняли слова буквально - как приказ построить деревянный забор.

Логос «знака» оракула и загадки в миме сочетали особую двусмысленность, характерную для самого логоса. Двузначность воплощалась как в раскрываемом, так и в скрываемом, о чем свидетельствуют сопутствующие 
коннотации. В поле семантики слово «логос» сводится к сокрытию истины (правды) и введению кого-то в заблуждение (см. Narecki, 1999). Двусмысленность слова «логос» означало, что оно, с одной стороны, вводило в заблуждение, а с другой - в силу своей истинности подлежало интеллектуальному разгадыванию (вычислению). Представляется, что двусмысленность логоса привела к тому, что слова воспринимались как объект этимологических исследований. Правильность коннотаций была в конечном счете искажена только в пределах этих слов. В то же время, если сначала в правильном угадывании смысла было видно божественное вдохновение, то позже слова подверглись толкованию, которое свидетельствовало прежде всего о мудрости и преимуществах интеллекта самого интерпретирующего.

Говоря о концепции символических форм, Фрейденберг заметила, что Кассирер отказался рассматривать мифологический образ и языковые представления в генетическом аспекте, а указал только, что родились они в один и тот же момент (см. Фрейденберг, 1997, с. 31). Для Кассирера миф и язык являлись примитивными и рудиментарными способами символического формирования фактов. И миф, и язык, хотя между ними не было никакой генетической зависимости, оказались выражением того же символического процесса создания реальности (см. Andrzejewski, 1980, p. 138). Фрейденберг, как и немецкий философ, подчеркивала социальную роль языка и его свободу в создании собственных форм выражения. Изучая и признавая сложную взаимосвязь между мифологической картиной и лингвистическим представлением, она сохраняла их несводимую друг к другу специфику. Это позволило ей интерпретировать греческую комедию, в которой элементом, соединяющим мим с философской диалектикой и религиозной сферой, учёная сделала загадку. Мим указывал образы, но также оперировал логосом - загадкой, интерпретированной аналогично образу. Смысл слов был укоренен в самих словах и их этимологии, как и смысл образов в самих образах. Так понимаемая комедия посредством сценического выступления и логоса-слова указывала истины, о которых шла речь в философии и которые мистерию сделали предметом загадки, невыразимой тайны.

\section{Благодарности}

Переводчик благодарит Giorgia Rimondi за помощь в работе с итальянским изданием Giorgio Colli, La nascita della filosofia.

\section{Список литературы}

Andrzejewski, B. (1980). Animal symbolicum. Ewolucja neokantyzmu Ernsta Cassirera. Poznań: Wydawnictwo Naukowe UAM.

Arystotle (1952). The Works of Aristotle. Volume 12: Select Fragments. Oxford: Clarendon Press. 
Galactica Media: Journal of Media Studies. 2021. No 3 | ISSN: 2658-7734

Общеюмористическая теория | https://doi.org/10.46539/gmd.v3i3.220

Burkert, W. (1987). Ancient mystery cults. Cambridge, Mass.: Harvard University Press.

Cassirer, E. (1946). Myth of the State. New Haven: Yale University Press.

Colli, G. (1989). La Nascita della filosofia. Milano: Adelphi.

Gigon, O. (1959). Grundprobleme der antiken Philosophie. Bern; München: Francke Verlag.

Grajewski, W. (2005). Przedmowie. In O. Freudenberg, Semantyka kultury. Kraków: TAiWPN Universitas.

Kowalski, A. P. (1999). Symbol w kulturze archaicznej. Poznań: Wydawnictwo Naukowe Instytutu Filozofii UAM.

Narecki, K. (1999). Logos we wczesnej myśli greckiej. Lublin: Redakcja Wydawnictw KUL.

Sójka, J. (1988). O koncepcji form symbolicznych Ernsta Cassirera. Warszawa: PWN.

Żyłko, B. (2007). Posłowiu. In O. Freidenberg, Obraz i pojęcie. Gdańsk: Wydawnictwo Uniwersytetu Gdańskiego.

Аристотель (2007). Поэтика. В Аристотель. Поэтика. Риторика (сс. 21-70). Санкт-Петербург: Издательство «Азбука».

Гераклит Эфесский (2012). Все наследие на языках оригинала и в русском переводе: Краткое издание. Москва: Ад Маргинем Пресс.

Геродот (1972). История в девяти книгах. Ленинград: Наука.

Кант, И. (1965). Пролегомены ко всякой будущей метафизике, могущей появиться как наука. В И. Кант. Сочинения в шести томах. Том 4; Часть 1 (сс. 67-189). Москва: Мысль.

Кант, И. (1966). Критика способности суждения. В И. Кант. Сочинения в шести томах. Том 5 (сс. 161-446). Москва: Мысль.

Кассирер, Э. (2000). Понятие символической формы в структуре наук о духе. В Э. Кассирер. Избранное: Индивид и космос (сс. 391-413). Москва; Санкт-Петербург: Университетская книга.

Фрейденберг, О. М. (1978). Миф и литература древности. Москва: Наука.

Фрейденберг, О. М. (1997). Поэтика сюжета и жанра. Москва: Лабиринт.

Фрейденберг, О. М. (1998). Образ и понятие. В О. М. Фрейденберг. Миф и литература древности (сс. 223-622). Москва: Издательская фирма «Восточная литература» РАН.

Фрейденберг, О. М. (2006). Идея пародии (набросок к работе). Вече: Журнал русской философии и культуры, (17), 230-240.

\section{References}

Andrzejewski, B. (1980). Animal symbolicum. Ewolucja neokantyzmu Ernsta Cassirera [Animal symbolicum. Evolution of Ernsta Cassirer's neokantianity]. Poznań: Wydawnictwo Naukowe UAM. (In Polish).

Aristotle (2007). Poetics. In Aristotle, Poetics. Rhetoric. (pp. 21-70). St. Petersburg: Azbuka Publishing House. (In Russian).

Arystotle (1952). The Works of Aristotle. Volume 12: Select Fragments. Oxford: Clarendon Press. 
Burkert, W. (1987). Ancient mystery cults. Cambridge, Mass.: Harvard University Press.

Cassirer, E. (1946). Myth of the State. New Haven: Yale University Press.

Cassirer, E. (2000). The concept of symbolic form in the structure of the sciences of the spirit. In E. Cassirer, Favorites: The individual and the cosmos (pp. 391-413). Moscow; St. Petersburg: University Book. (In Russian).

Colli, G. (1989). La Nascita della filosofia [The birth of philosophy]. Milano: Adelphi. (In Italian).

Freidenberg, O. M. (1978). Myth and literature of antiquity. Moscow: Nauka. (In Russian).

Freidenberg, O. M. (1997). The poetics of the plot and genre. Moscow: Labyrinth. (In Russian).

Freidenberg, O. M. (1998). Image and concept. In O. M. Freidenberg, Myth and literature of antiquity (pp. 223-622). Moscow: Publishing Company "Oriental Literature" of the Russian Academy of Sciences. (In Russian).

Freidenberg, O. M. (2006). The idea of a parody (a sketch for the work). Veche: Journal of Russian Philosophy and Culture, (17), 230-240. (In Russian).

Gigon, O. (1959). Grundprobleme der antiken Philosophie [Basic problems of ancient philosophy]. Bern; München: Francke Verlag. (In German).

Grajewski, W. (2005). Przedmowie [Preface]. In O. Freudenberg, Semantyka kultury [Semantics of Culture]. Kraków: TAiWPN Universitas. (In Polish).

Heraclitus of Ephesus (2012). All the heritage in the original languages and in Russian translation: a short edition. Moscow: Ad Marginem Press.

Herodotus (1972). History in nine books. Leningrad: Nauka. (In Russian).

Kant, I. (1965). Prolegomena to any future metaphysics that may appear as a science. In I. Kant, Works in six volumes. Vol. 4, part 1. (pp. 67-189). Moscow: Mysl. (In Russian).

Kant, I. (1966). Criticism of the ability of judgment. In I. Kant, Works in six volumes. Vol. 5. (pp. 161-446). Moscow: Mysl. (In Russian).

Kowalski, A. P. (1999). Symbol w kulturze archaicznej [Symbol in archaic culture]. Poznań: Wydawnictwo Naukowe Instytutu Filozofii UAM. (In Polish).

Narecki, K. (1999). Logos we wczesnej myśli greckiej [Logos in early Greek thought]. Lublin: Redakcja Wydawnictw KUL. (In Polish).

Sójka, J. (1988). O koncepcji form symbolicznych Ernsta Cassirera [On Ernst Cassirer's concept of symbolic forms]. Warszawa: PWN. (In Polish).

Żyłko, B. (2007). Posłowiu [Afterword]. In O. Freidenberg, Obraz i pojęcie [Image and concept]. Gdańsk: Wydawnictwo Uniwersytetu Gdańskiego. (In Polish). 